\title{
Risk and Return Relationship -An Empirical Study of BSE Sensex Companies in India
}

\author{
Bedanta Bora*, Anindita Adhikary \\ Department of Management Studies, Sikkim Manipal Institute of Technology, India
}

Copyright (C 2015 Horizon Research Publishing, All Rights Reserved.

\begin{abstract}
Investment in stock market is subjected to diverse risks. The same is made in expectation of return which is in excess of a risk-free rate. The actual return the investor receives from stock may vary from his expected return and risk is expressed in terms of variability of return. As such, it becomes essential to understand magnitude of the rate of returns and the degree of risk involved. One noteworthy measure of systematic risk associated with an investment is Beta. It refers to the volatility of a stock in comparison with rest of the market. The stability of beta is of great significance as it happens to be an important tool for investment decision. In these contexts, the study has explored the relationship between returns of securities and market returns and also the stability of beta for a variety of stocks that formed a part of BSE Sensex. The methodology adopted here is empirical in nature. The required information for undergoing the research has been accumulated from secondary sources. The sample size for this study consists of 30 corporate firms that are listed on BSE and included in Sensex. Descriptive statistics and multiple regression model are being used to study the relationship between returns of securities and market returns. Stability of beta is tested as well. Findings indicate that there seems to be positive association between returns of securities and market returns and betas are unstable overtime.
\end{abstract}

Keywords Sensex, Risk, Beta, Security Returns, Market Returns

\section{Introduction}

Investment in stock market is characterized by return and risk. The return may be in the form of yield or capital appreciation. Risk is the uncertainty of a future outcome. The return to be generated in future period is known as the expected return. The actual return over some past period is known as the realized return. The realized return on an asset may vary from expected return. Volatility may be described as the range of movement from the expected level of return. The more a stock fluctuates, the more volatile the stock is. This is because of the fact that the wide price variations create more uncertainty of an eventual outcome.
Risk consists of two components, the systematic risk and unsystematic risk. The systematic risk is caused by factors external to the particular company and uncontrollable by the company. It affects the market as a whole. In case of unsystematic risk the factors are specific, unique and related to the particular industry and company. Virtually all securities have some systematic risk, whether bonds or stocks, because systematic risk directly encompasses interest rate, market, and inflation risks. The investor cannot escape this part of the risk because no matter how well he diversifies, the risk of the overall market cannot be avoided. If the stock market declines sharply, most stocks will be adversely affected; if it rises strongly, most stocks will appreciate in value.

Risk measurement and analysis has been a critical issue for any investment decision because risk can be transferred but cannot be eliminated from the system. The estimation of risk is the key to any investment decisions.

\section{Review of Literature}

Numerous studies have been devoted to study the relationship between risk and return and the pricing of securities in the market. Most of the studies have been undergone on developed markets and a few have been on Indian market. Sharpe [18], Linter [12] and Mossin [13] have independently developed the model of linear general equilibrium for asset returns in securities market. This model came to be known as Sharpe-Lintner-Mossin form of Capital Assets Pricing Model (CAPM). The model was served to understand the complex relationship between returns and risks of securities. The model argues that beta or the systematic risk is the only relevant risk measure for investment in stock market and a positive trade-off between beta and expected returns should exist. The growing importance of risk and return has made it the most extensively tested financial models in the literature. Black [1], Black, Jensen and Scholes [2], Fama and Macbeth [6], Fama and French [4], Fama and French [5] have focused their research on some of the issues related to CAPM. However, the findings of these researchers are arguable and debatable.

Chan and Lakonishok [3], Kothari, Shanken and Sloan 
[11], Kim [10] and Jagannathan and Wang [9] have revealed a positive relationship between return and beta. Pettengill, Sundaram and Mathur [14] developed a conditional relationship between return and beta which depends on whether the excess return on the market index is positive or negative. They established that in periods when the excess market return is positive there is a significant positive relationship between beta and return. In periods when the excess market return is negative, there is a negative relationship between beta and return. Kothari, Shanken and Sloan [11] found that using betas estimated from annual rather than monthly returns produces a stronger positive relation between average return and beta. Isakov [8] investigated the Swiss stock market for the period from 1983 to 1991 . He disclosed that beta is statistically significant related to realized returns and has concluded that beta is a good measure of risk.

Poon and Granger [15] in their study concluded that volatility has a very wide sphere of influence in investment, security valuation, risk management and policy making. They have further emphasized on the importance of volatility forecasting in various spheres of financial risk management and options pricing. Seth and Saloni [17] examined the volatility of common stock over the period of 1980 to 2003 . The study concluded that the stock market follow a deterministic path implying that stock returns oscillate between excess return and under return. Haddad [7] investigated the degree of return volatility persistence and time varying behavior of systematic risk of two Egyptian stock portfolios during the period January 2001 to June 2004. The findings revealed that the small stocks portfolio exhibits differences in volatility persistence and time variability. The study further revealed that the volatility persistence of each portfolio and its market risk are significantly positively related. Rao, Kanagaraj and Tripathy [16] carried out a study on the impact of individual stock futures on the underlying stock market volatility in India from June 1999 to July 2006 using GARCH and ARCH model. The study revealed that the stock future derivatives do not affect stock market volatility; rather there are other factors responsible for the same. Thus, the investment in stock market requires the study of the relationship between risks and return.

\section{Objectives of the Study}

The basic framework of this study is risk and return relationship analysis. This study is undertaken with the following objectives-

(a) To ascertain the relationship between returns of securities and market returns.

(b) To test the stability of beta for 30 companies of BSE Sensex

\section{Hypothesis}

Keeping the objectives in view, the hypothesis developed for the study is

$\mathrm{H}_{0}$ : There is no relationship between returns of securities and market returns

$\mathrm{H}_{\mathrm{a}}$ : There is a positive relationship between returns of securities and market returns

\section{Materials and Methods}

\subsection{Nature of Research}

The present research is exploratory and empirical in nature with descriptive statistics based on the monthly returns of stock market index - BSE Sensex and 30 companies of the Sensex.

\subsection{Research Design}

The research design for the study is conclusive in nature as conclusive research tests hypothesis of the problem and draws definite conclusion for implementation.

\subsection{Population and Sample}

The risks and returns have been analyzed using the monthly closing prices of 30 companies and BSE Sensex. The return and risk based on Sensex have been taken as the measurement of market return and market risk, respectively. Sensex represents the major market capitalization on BSE and hence has been taken as a proxy for market portfolio.

\subsection{Period of the Study}

The period of study is from Jan 2010 to Dec 2013. This period is chosen because the index has witnessed tremendous fluctuation during the same period.

\subsection{Data Collection}

The study is based on secondary data. The data used for study is extracted from CMIE database Prowess.

\subsection{Data Analysis}

The monthly closing price for each month is taken and monthly rate of return on each of the stock is computed by using the formula :

\section{Where}

$$
\mathrm{r}_{\mathrm{jt}}=\left(\mathrm{P}_{\mathrm{j}, \mathrm{t}}-\mathrm{P}_{\mathrm{j}, \mathrm{t}-1}\right) / \mathrm{P}_{\mathrm{j}, \mathrm{t}-\mathrm{1}} * 100
$$

$\mathrm{r}_{\mathrm{jt}}=$ Monthly rate of return of stock $\mathrm{j}$ in the time period $\mathrm{t}$,

$\mathrm{P}_{\mathrm{j}, \mathrm{t}}=$ Monthly closing price of stock $\mathrm{j}$ in the time period $\mathrm{t}$, and

$\mathrm{P}_{\mathrm{j}, \mathrm{t}-\mathrm{1}}=$ Monthly closing price of stock $\mathrm{j}$ in the time period $\mathrm{t}$ $-1$

The monthly market rate of return is computed using the formula

Where

$$
\mathrm{m}_{\mathrm{t}}=\left(\mathrm{B}_{\mathrm{t}}-\mathrm{B}_{\mathrm{t}-1}\right) / \mathrm{B}_{\mathrm{t}-1} * 100
$$

$\mathrm{m}_{\mathrm{t}}=$ Market return at the time period $\mathrm{t}$

$\mathrm{B}_{\mathrm{t}}=$ Sensex value at the time period $\mathrm{t}$, and

$\mathrm{B}_{\mathrm{t}-1}=$ Sensex value at the time period $\mathrm{t}-1$

Beta is used for analyzing the market risk. Beta is calculated by using following relationship.

$$
\mathrm{R}_{\mathrm{i}}=\mathrm{a}+\beta_{\mathrm{i}} \mathrm{R}_{\mathrm{m}}
$$


Where

$\mathrm{R}_{\mathrm{i}}=$ expected return of companies

$\beta_{\mathrm{i}}=$ Market sensitivity of companies (Beta)

$\mathrm{R}_{\mathrm{m}}=$ expected return of Sensex

To test for normality of the distributions of monthly returns, the mean return data is analyzed using measures such as standard deviations, kurtosis and skewness. For confirming to normal distribution, skewness and kurtosis should be equal to 0 and 3 respectively. Zero skewness implies symmetry in the distribution whereas kurtosis indicates the extent to which probability is concentrated in the centre and especially at the tail of the distribution. Generally, kurtosis greater than three (Kurtosis $>3$ ) indicates extreme leptokurtic and kurtosis less than three (Kurtosis $<3$ ) indicates extreme platorkurtic.

Multiple regression analysis is further used in the study to statistically predict the value of a dependent variable i.e. Sensex by several independent or explanatory variable i.e. companies. In multiple regression, the coefficient of multiple regression ( $\mathrm{R}$ square) is the proportion of variation in Sensex that is explained by the combination of 30 companies. The adequacy of the regression model can be verified by testing the significance of the overall regression model and coefficients of regression. The contribution of an independent variable can be determined by applying partial $\mathrm{F}$ statistics.

5.7. Limitation of the Study: The present study has the under-mentioned limitations-

(i) Sensex is an index with a small number of companies. Thus, the small number of companies does not give us much confidence in estimating beta coefficients, because of the possible arise of error.

(ii) In calculating beta coefficients, the existence of high volatility of beta is noticed between different periods. Thus, instead of using only four years' period for the estimation of betas, it should be better to expand this period to ten years or even more than that.

Table 1. Descriptive Statistics of the Returns

\begin{tabular}{|c|c|c|c|c|c|c|}
\hline Company & Minimum & Maximum & Mean & Standard Deviation & Skewness & Kurtosis \\
\hline $\mathrm{ACC}$ & -17.8896 & 15.6633 & 0.773267 & 7.2699302 & -0.070 & -0.349 \\
\hline Bharat Heavy Electricals & -80.5852 & 23.0094 & -3.325375 & 14.8623311 & -2.996 & 15.506 \\
\hline Bharti Airtel & -18.1409 & 25.3346 & 0.584829 & 9.4024774 & 0.361 & -0.219 \\
\hline DLF & -23.3088 & 26.0080 & -0.722047 & 12.3051233 & 0.355 & -0.617 \\
\hline Grasim Industries & -33.1861 & 17.5704 & 0.456262 & 8.1995421 & -1.305 & 5.202 \\
\hline HDFC Bank & -80.5243 & 16.3357 & 0.099904 & 13.8484801 & -4.343 & 25.480 \\
\hline HDFC & -79.0306 & 16.7720 & -0.504260 & 13.1998281 & -4.681 & 28.000 \\
\hline Hindalco Industries & -15.6268 & 26.6955 & 0.098384 & 10.1287746 & 0.533 & -0.262 \\
\hline HUL & -13.1764 & 25.2092 & 2.042516 & 6.8317350 & 0.793 & 2.118 \\
\hline ICICI Bank & -23.2509 & 31.7558 & 1.109969 & 10.3782723 & 0.502 & 1.295 \\
\hline Infosys Technologies & -22.6807 & 20.2825 & 1.089624 & 8.5090192 & -0.294 & 0.710 \\
\hline ITC & -47.3198 & 13.4023 & 1.054165 & 9.0585714 & -3.345 & 17.316 \\
\hline Jaiprakesh Associates & -32.3063 & 36.6762 & -0.912503 & 14.6913295 & 0.521 & 0.191 \\
\hline L\&T & -39.7180 & 31.7054 & 0.125100 & 11.8736317 & -0.326 & 2.543 \\
\hline $\mathrm{M} \& \mathrm{M}$ & -45.8778 & 13.7600 & 0.427322 & 9.9366948 & -2.369 & 9.254 \\
\hline Maruti Suzuki & -19.2313 & 30.4095 & 1.047255 & 10.7231714 & 0.665 & 0.835 \\
\hline NTPC & -10.1199 & 13.4960 & -0.740829 & 6.5857254 & 0.612 & -0.438 \\
\hline ONGC & -77.0158 & 27.0432 & -1.097437 & 13.5248337 & -3.753 & 21.994 \\
\hline Ranbaxy Laboratories & -20.4529 & 42.4598 & 0.626042 & 11.5571355 & 0.828 & 2.558 \\
\hline Reliance Communications & -29.8532 & 75.7246 & 1.133792 & 19.9150994 & 1.440 & 3.204 \\
\hline Reliance Industries & -13.1349 & 17.6865 & -0.082157 & 7.1704485 & 0.199 & -0.691 \\
\hline Reliance Infrastructure & -22.6195 & 57.4093 & -0.901563 & 14.7135927 & 1.493 & 4.021 \\
\hline SBI & -18.0995 & 27.2646 & 0.088872 & 9.3180692 & 0.591 & 0.699 \\
\hline Sterlite Industries & -74.3758 & 29.0737 & -2.599362 & 14.8896693 & -2.296 & 11.144 \\
\hline Sun Pharmaceutical & -78.7050 & 16.2461 & 0.134556 & 15.1280889 & -3.665 & 17.028 \\
\hline TCS & -12.4412 & 19.5403 & 2.524048 & 6.4035492 & 0.301 & 0.054 \\
\hline Tata Motors & -78.9538 & 36.5471 & 1.030328 & 16.8057893 & -2.246 & 10.567 \\
\hline Tata Power & -90.4438 & 19.0258 & -2.261364 & 15.4704216 & -4.050 & 23.238 \\
\hline Tata Steel & -21.2199 & 34.5265 & 0.134740 & 12.7286103 & 0.702 & 0.300 \\
\hline Wipro & -42.4329 & 25.0143 & 0.320796 & 10.6862020 & -1.207 & 4.928 \\
\hline
\end{tabular}




\section{Empirical Results and Discussion}

A summary of descriptive statistics of the daily returns for 30 companies of Sensex is given in table 1 . Among the 30 companies, 20 companies have registered positive mean return for all months throughout the study period. The highest mean return is reported in TCS while lowest mean return is registered in Bharat Heavy Electricals. Standard deviation of returns for Reliance is found to be largest, while that for TCS is the lowest of all. Lesser deviation indicates least volatile and higher deviation denotes most volatile. The skewness of the daily return is found to be positive for 15 companies and negative for other 15 companies. The positively skewed implies that the return distribution of the companies traded in the market have a higher probability of earning positive return than negatively skewed. The kurtosis of the daily mean return for all companies is excessive, thus suggesting the presence of leptokurtosis.

Table 2. Model Summary

\begin{tabular}{|c|c|c|c|c|}
\hline Model & $\mathrm{R}$ & R Square & Adjusted R Square & $\begin{array}{c}\text { Std. Error of the } \\
\text { Estimate }\end{array}$ \\
\hline 1 & $0.995^{\mathrm{a}}$ & 0.990 & 0.970 & 0.8759648 \\
\hline
\end{tabular}

Table 2 shows the summary of the regression model. The $\mathrm{R}$ square value shows the degree of the strength / association of the regression model. The $\mathrm{R}$ square value of 0.990 shows that $99 \%$ of variation in the dependent variable (Sensex) is explained by the independent variables (Scripts). A value close to 1 indicates that the strength of the regression model is good. The adjusted R square of 0.970 shows that on inclusion of another independent variable, the strength of the model will come down from $99 \%$ to $97 \%$ respectively.

The ANOVA (Analysis of Variance) table 3 shows the F value which is $50.614(0.000)$. The model is statistically significant@5\%(0.000<0.05). The coefficient table 4 portrays how many coefficients are individually significant. 15 companies have $t$ value more than 1.96 which indicates that they fall under the rejection region. Hence the null hypothesis is rejected and the alternate hypothesis is accepted. There is $95 \%$ confidence that there is a positive relationship between returns of securities and market returns. The variable with highest effect on Sensex is Reliance industries followed by Infosys Technologies, Tata Motors, ICICI Bank, Bharti Airtel, ITC, ACC and SBI. Thus, while making investment decision, an investor can consider those companies that have high positive influence on the Sensex (as and when the market is favorable).

Table 3. ANOVA ${ }^{\mathrm{b}}$

\begin{tabular}{|c|c|c|c|c|c|c|}
\hline \multicolumn{2}{|c|}{ Model } & Sum of Squares & df & Mean Square & F & Sig. \\
\hline \multirow{2}{*}{1} & Regression & 1165.096 & 30 & 38.837 & 50.614 & $0.000^{\mathrm{a}}$ \\
\cline { 2 - 7 } & Residual & 12.277 & 16 & 0.767 & & \\
\cline { 2 - 7 } & Total & 1177.373 & 46 & & & \\
\hline
\end{tabular}

a. Predictors: (Constant), Wipro, Grasim Industries, ITC, ONGC, HDFC Bank, Bharat Heavy Electricals, Ranbaxy Laboratories Sun Pharmaceutical, Tata Motors, M\&M, Bharti Airtel, HUL, TCS, Reliance Industries,

Hindalco Industries, Infosys Technologies, NTPC, SBI, Reliance

Communications, DLF, Sterlite Industries, L\&T, Reliance Infrastructure,

Maruti Suzuki, HDFC, ACC, Tata Power, Jaiprakesh Associates, Tata Steel, ICICI Bank

b. Dependent Variable: Sensex

A stable beta of a company over time can be taken as a signal for the future market risk. An unstable beta over time should be reorganized at regular intervals such that it arrests the potential risk of the company with least error. To investigate the stability of beta, the values of betas for different companies have been estimated. Table 5 reveals that the values of betas for different companies from 2010 to 2013. The table shows that betas for different companies have not been stable during the study period. The betas of some companies have increased during the study period while betas for some other companies have declined. The companies for which the risks have increased are ICICI Bank, Jaiprakesh Associates, L\&T and ONGC. Betas of most of the companies have been fluctuating during the study period. Thus, the analysis shows that betas for all the companies have not been stable. Betas should be reorganized at regular intervals such that it arrests the potential risk of the company in the future precisely. In other words, an investor should be cautious while structuring his portfolio. His portfolio should comprise of those scripts which are stable in nature to avoid fluctuation in the return generated by the portfolio. However, he should also keep in mind that if beta is less than 1, the script return is less volatile compared to the market return, if the beta is more than 1 , script return is more volatile compared to the market return and negative beta value indicates that the script return moves in the opposite direction to the market return. So, an investor according to his risk bearing ability may prefer to invest in a particular script. 
Table 4. Coefficients ${ }^{\mathrm{a}}$

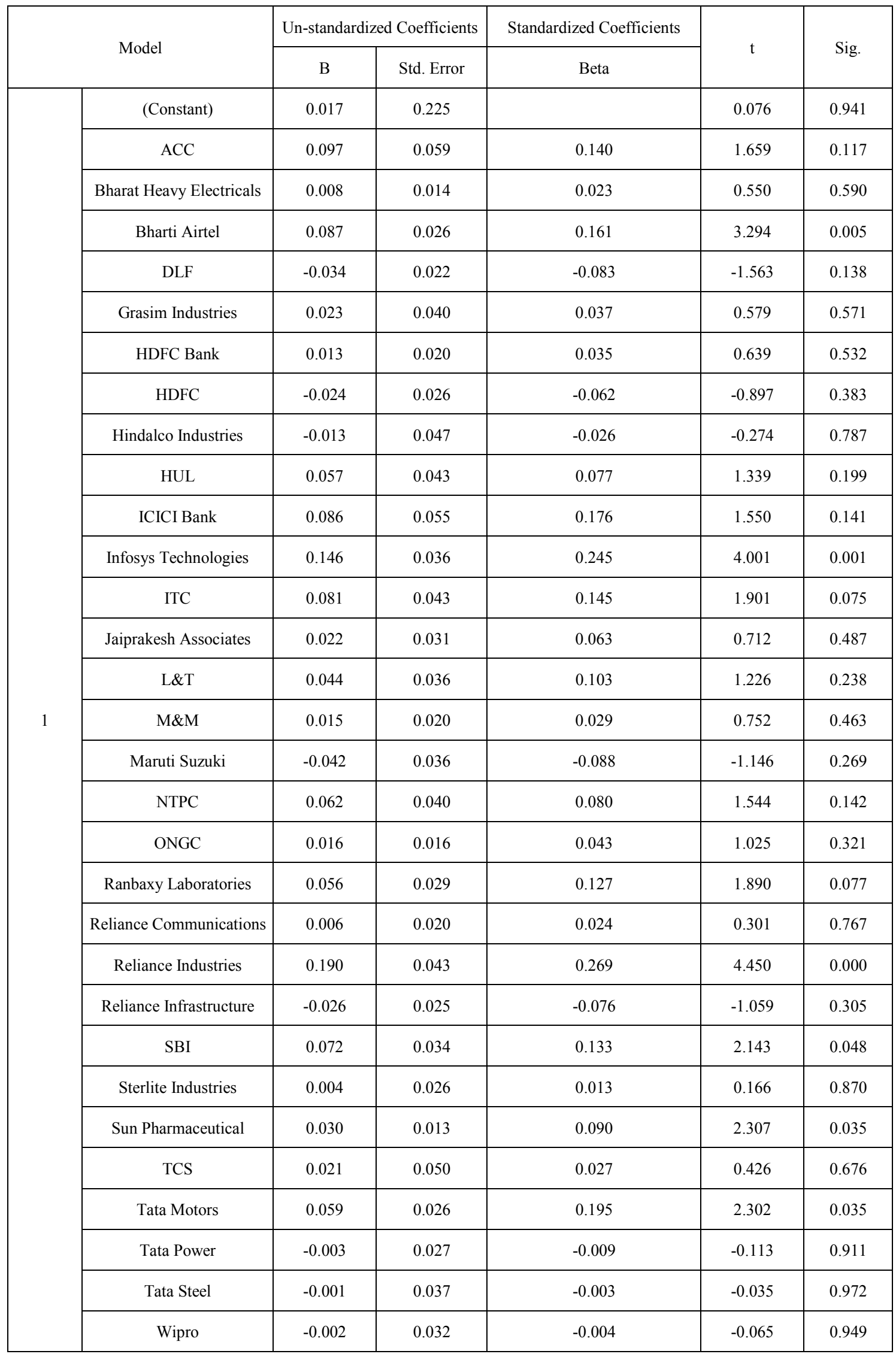


Table 5. Stability of Beta

\begin{tabular}{|c|c|c|c|c|c|c|}
\hline BSE Companies & 2010 & 2011 & 2012 & 2013 & Mean & SD \\
\hline $\mathrm{ACC}$ & 1.22 & 0.73 & 0.95 & 1.22 & 1.03 & 0.24 \\
\hline Bharat Heavy Electrical & 0.72 & -1.36 & 1.55 & 1.96 & 0.72 & 1.48 \\
\hline Bharti Airtel & 1.03 & 0.75 & 0.91 & 1.77 & 1.12 & 0.45 \\
\hline DLF & 2.05 & 1.85 & 1.55 & 1.82 & 1.82 & 0.21 \\
\hline Grasim Industries & 1.45 & 0.43 & 1.04 & 1.33 & 1.07 & 0.46 \\
\hline HDFC Bank & 1.26 & 1.30 & 1.09 & 1.20 & 1.21 & 0.09 \\
\hline HDFC & 1.81 & 0.98 & 0.44 & 1.20 & 1.11 & 0.57 \\
\hline Hindalco Industries & 1.68 & 0.67 & 1.67 & 0.39 & 1.10 & 0.67 \\
\hline HUL & 1.11 & 0.59 & -0.28 & 0.31 & 0.43 & 0.58 \\
\hline ICICI Bank & 0.97 & 1.48 & 2.06 & 2.87 & 1.85 & 0.81 \\
\hline Infosys Technologies & 0.84 & 1.18 & 0.60 & -0.16 & 0.62 & 0.57 \\
\hline ITC & 1.18 & 0.73 & 0.32 & 0.81 & 0.76 & 0.35 \\
\hline Jaiprakesh Associates & 1.62 & 1.73 & 2.64 & 3.39 & 2.34 & 0.83 \\
\hline L\&T & 0.84 & 1.16 & 2.10 & 2.46 & 1.64 & 0.77 \\
\hline M\&M & -0.79 & 1.12 & 0.69 & 1.00 & 0.50 & 0.88 \\
\hline Maruti Suzuki & 1.13 & 0.85 & 1.96 & 2.64 & 1.64 & 0.82 \\
\hline NTPC & 1.07 & 1.05 & 0.90 & 0.76 & 0.94 & 0.14 \\
\hline ONGC & 0.28 & 0.75 & 0.91 & 1.67 & 0.90 & 0.58 \\
\hline Ranbaxy Laboratories & 0.91 & 0.62 & -0.20 & -0.01 & 0.33 & 0.52 \\
\hline Reliance Communications & 2.32 & 1.88 & 3.41 & 2.86 & 2.62 & 0.66 \\
\hline Reliance Industries & 1.03 & 1.02 & 1.14 & 0.98 & 1.04 & 0.07 \\
\hline Reliance Infrastructure & 1.14 & 1.84 & 3.77 & 2.12 & 2.22 & 1.12 \\
\hline SBI & 0.85 & 0.78 & 1.86 & 1.80 & 1.32 & 0.59 \\
\hline Sterlite Industries & 0.80 & 1.43 & 1.84 & 0.37 & 1.11 & 0.65 \\
\hline Sun Pharmaceutical & 3.06 & 0.59 & 0.70 & 0.89 & 1.31 & 1.17 \\
\hline TCS & 0.43 & 0.51 & -0.07 & -0.54 & 0.08 & 0.49 \\
\hline Tata Motors & 0.47 & 1.68 & 2.43 & 1.24 & 1.46 & 0.82 \\
\hline Tata Power & 1.36 & 0.98 & 1.65 & 0.86 & 1.21 & 0.36 \\
\hline Tata Steel & 2.31 & 1.31 & 2.09 & 0.87 & 1.64 & 0.67 \\
\hline Wipro & 0.53 & 0.75 & 0.54 & -0.83 & 0.25 & 0.72 \\
\hline
\end{tabular}

\section{Conclusions}

Investment in stock market is subjected to diverse risks. The actual return the investor receives from scripts may vary from his expected return and risk is expressed in terms of variability of return. Thus it is essential to understand the magnitude of the rate of returns and the degree of risk involved. This paper has attempted to ascertain the relationship between returns of securities and market returns and to test the stability of beta for 30 companies of BSE Sensex. The descriptive statistics, multiple regression analysis and beta estimation were worked out. The study concluded that $99 \%$ of variation in Sensex is explained by the variation in Scripts. There is $95 \%$ confidence that there is a positive relationship between returns of securities and market returns. The scripts with highest effect on Sensex are
Reliance Industries followed by Infosys Technologies, Tata Motors, ICICI Bank, Bharti Airtel, ITC, ACC and SBI. Further, betas for different companies have not been stable during the study period. Analysis of betas reflects that betas of most of the companies have been fluctuating during the study period. The betas of some companies have increased during the study period while betas for some other companies have declined. The companies for which the risks have increased are ICICI Bank, Jaiprakesh Associates, L\&T and ONGC. Thus, while making investment decision, an investor can consider those companies which have high positive influence on the Sensex when the market is favorable. Moreover, his selection should comprise of those scripts which are stable in nature to avoid fluctuation in the return generated by his portfolio. So, an investor according to his risk bearing ability may prefer to invest in a particular 
script.

\section{Further Research}

Future research could explore the relationship between returns of securities across other major indices.

\section{REFERENCES}

[1] Black, F.(1972), "Capital Market Equilibrium with Restricted Borrowing", Journal of Business, 45.

[2] Black, F., Jensen, M.C. and Scholes, M. (1972), "Studies in Theory of Capital Markets", New York : Praeger.

[3] Chan, K. C. and Lakonishok, J. (1993), “Are the Reports of Beta's Death Premature?", Journal of Portfolio Management, 19, pp 51-62.

[4] Fama, E. and French, K. (1992), "The Cross-section of Expected Stock Returns”, Journal of Finance, 47, pp 427-465.

[5] Fama, E. and French, K. (1996), "The CAPM is Wanted, Dead or Alive", Journal of Finance, 51(5), pp 1947-1958.

[6] Fama, E. and Macbeth, J. D., (1973), "Risk, Return and Equilibrium: Empirical Test", Journal of Political Economy, 81, pp 607-636.

[7] Haddad, M. M. (2007), “An Intertemporal Test of the Beta Stationery: The case of Egypt", Middle East Business and Economics Review, Vol 19, No. 1.

[8] Isakov, D. (1999), "Is Beta still alive? Conclusive evidence from the Swiss stock market", European Journal of Financ, 5(3), pp 202-212.

[9] Jagannathan, R. and Wang, Z. (1996), "The conditional CAPM and the cross-section of expected returns", Journal of Finance, 51, pp 3-53.

[10] Kim, D. (1995), "The Errors in the Variables Problems in the Cross-section of Expected Stock Returns", Journal of Finance, 50, pp 1605-1634.

[11] Kothari, S. P., Shanken, J. and Sloan, R. G. (1995), “Another look at the Cross-section of Expected Stock Returns", Journal of Finance, 50, pp 185-224.

[12] Linter, John (1965), "Security Prices, Risk and Maximal gains from Diversification”, Journal of Business, pp 294-419.

[13] Mossin, Jan (1968), “Optimal Multi-Period Portfolio Policies”, Journal of Business, 4(2), pp 215-229.

[14] Pettengill, G., Sundaram, S. and Mathur, I. (1995), "The Conditional Relation between Beta and Return", Journal of Finance and Quantitative Analysis, 30, pp 101-116

[15] Poon, S. and Granger, C. (2003), "Forecasting Volatility in Financial Markets: A Review", Journal of Economic Literature, 41, pp 478-539.

[16] Rao, Ramana, Kanagaraj, S. V. A. and Tripathy, N. (2008), "Does Individual Stock Futures affect Stock Market Volatility in India?", Journal of the Indian Institute of Economics, Vol 50, No. 1, pp 125-135.

[17] Seth, A. K. and Saloni, G. (2005), "Understanding Volatility at BSE: A Quality Control Approach", 32, Decision, Jan-June.

[18] Sharpe, William F. (1964), "Capital Asset Prices : A Theory of Market Equilibrium under Conditions of Risk", Journal of Finance, 19(3), pp 425-442. 